\section{Effects of different mechanical treatments on Quercus variabilis, $Q$. wutaishanica and $Q$. robur acorn germination}

\author{
Yan Liu ${ }^{(1)}$, Longyu Hou ${ }^{(2)}$, Qingmei Li ${ }^{(1)}$
}

Delayed and uneven germination of acorns has a negative effect on seedling quality and yield in seedlings. To address this issue, the effects of different mechanical treatments were studied, including a control (CK), removal of cup scar (RS), removal of pericarp (RP), removal of pericarp and $1 / 2$ of the cotyledon (HC) and removal of pericarp and 2/3 cotyledon (TC), on the germination of Quercus variabilis, $Q$. wutaishanica and $Q$. robur acorns and pericarp thickness. The results showed that (1) RP and HC treatments significantly decreased root and shoot mean germination time, increased rooting and shooting germination percentage, and improved the root and shoot synchronization and vigor indexes of the three species' acorns; (2) the acorns from the TC treatment significantly reduced root and shoot mean germination time and significantly induced the root and shoot synchronization index for all three species; and (3) the RS treatment significantly reduced the root and shoot mean germination time of the three species. Therefore, RP and HC treatments can effectively accelerate germination and regular seedling, which are important in the propagation of $Q$. variabilis, $Q$. wutaishanica and $Q$. robur seedlings. Even and quick germination help reduce acorn predation.

Keywords: Pericarp and Cotyledon Excision, Pericarp Thickness, Acorn Germination, Quercus wutaishanica

\section{Introduction}

Due to their richness in proteins and carbohydrates, acorns are very attractive to animals as a food source and suffer heavy predation by a number of consumers. It is well documented that resistance and tolerance to biotic and abiotic stresses are alternative defense strategies for plants (Siemens et al. 2003). These mechanisms prevent consumption from predators using a number of physical barriers and chemical defenses (Hulme \& Benkman 2002, Yi \& Yang 2010): (1) to escape certain pathogens or insects, the time of first and last acorn germinations can differ by up to several weeks (Suszka et al. 2000), which leads to asynchronous germination (Giertych \& Suszka 2010); (2) under moderate conditions, the biomass remaining in the cotyledon serves as a reserve that can be used for seedling growth and survival, and the remaining biomass is used to defend against such stress factors as frequent shoot destruction, low light and low soil fertility (Frost \& Rydin 1997, Dalling \& Harms 1999, Kabeya \& Sakai 2003); (3) chemical defense by plant secondary metabolites, e.g., coumarin, quinine, tannins (Shimada 2001, Takahashi et al. 2010). While these mechanisms assist oak acorns during germination, they have a negative effect on seedling quality in a nursery setting, where fast and simultaneous germination is required. If germination time is long, the earlier plants quickly develop leaves that may overshadow neighboring seedlings and restrict access to water (Giertych \& Suszka 2011).

Over the past several decades, numerous studies have found that acorns of many oak species exhibit characteristics of low germination percentage (Bonner \& Vozzo 1987)
(1) State Key Laboratory of Tree Genetics and Breeding, Research Institute of Forestry, Chinese Academy of Forestry, Beijing 100091 (China); (2) Grassland Science Department, Animal Science and Technology, China Agricultural University, Beijing 100193 (China)

@ Qingmei Li (liqm99@163.com)

Received: Aug 06, 2014 - Accepted: Jan 23, 2015

Citation: Liu Y, Hou L, Li Q, 2015. Effects of different mechanical treatments on Quercus variabilis, $Q$. wutaishanica and $Q$. robur acorn germination. iForest 8: 728-734 [online 201505-05] URL: http://www.sisef.it/iforest/contents/?id=ifor1423-008

Communicated by: Gianfranco Minotta

and delayed and irregular germination in field and laboratory experiments (Suszka et al. 2000, Giertych \& Suszka 2011). Several feasible practice technologies and their associated mechanisms have been published for some oak species popular in Europe, North America and Asia (Suszka et al. 2000, Suszka 2006, Yi \& Zhang 2008, Hou et al. 2010, Giertych \& Suszka 2011). Removing pericarp can increase germination percentage, and cutting off parts of the distal end of the cotyledons can induce faster emergence and improve germination percentage (Suszka 2006, Hou et al. 2010, Giertych \& Suszka 2011). Our previous work on the acorns of Q. aliena var. acuteserrata has supported these results (Liu et al. 2012). Moreover, previous studies on mechanical scarification have dealt exclusively with acorn germination and seedling emergence (Giertych \& Suszka 2011). The consequences of mechanical scarification for roots are poorly understood.

We chose three oak species to test the effects of mechanical treatments on acorn germination and seedling growth. These species were selected because: (1) of the proven resistance of the pericarp of $Q$. variabilis, restricting water uptake and gas exchange (Sobrino-Vesperinas \& Viviani 2000), and the cutting off of different parts of the cotyledon having provoked different effects on $Q$. $v a$ riabilis acorn germination (Hou et al. 2010); (2) several similar studies have been conducted on $Q$. robur acorns, but the results are inconsistent (Suszka 2006, Rakić et al. 2006, Giertych \& Suszka 2011); (3) Q. wutaishanica is an important and common species in warm temperate zone deciduous forest in China. The time from root to shoot germination is long, and our previous research indicated that mechanical treatments affect root and shoot emergence of $Q$. aliena var. acuteserrata (Liu et al. 2012). The aim of this study was to determine the effects of mechanical treatments on delayed and asynchronous germination of three oak species, and whether the effects are the same among the different species. We also analyzed the role that pericarp thickness plays in acorn germination, and assumed that the thinner the pericarp, the more easily the shoot could emerge from the apex.

\section{Materials and methods}

Acorn collection and treatment

In mid-September of 2009, acorns of $Q$. variabilis, $Q$. wutaishanica and $Q$. robur were collected from multiple trees growing in the Beijing Botanical Garden of the Chinese Academy of Sciences $\left(116^{\circ} 20^{\prime} \mathrm{E}, 39^{\circ}\right.$ $\left.56^{\prime} \mathrm{N}\right)$. The mother tree characteristics of $Q$. variabilis, $Q$. wutaishanica and $Q$. robur acorns are presented in Tab. 1. 
Tab. 1 - Characteristics of Quercus variabilis, Q. wutaishanica and Q. robur trees from which acorns were collected. (DBH): diameter at breast height.

\begin{tabular}{lcccccc}
\hline Tree Species & DBH & $\begin{array}{c}\text { Plant height } \\
(\mathbf{m})\end{array}$ & $\begin{array}{c}\text { Clear bole } \\
\text { height }(\mathbf{m})\end{array}$ & $\begin{array}{c}\text { Crown width } \\
\text { EW/NS (m) }\end{array}$ & $\begin{array}{c}\text { Quantity } \\
\text { (kg) }\end{array}$ & $\begin{array}{l}\text { Acorn } \\
\text { maturity time }\end{array}$ \\
\hline Q. variabilis & 29 & 12 & 4.5 & $7.5 / 6.2$ & 10 & late August \\
Q. wutaishanica & 33 & 5.7 & 2.2 & $8.0 / 7.4$ & 10 & mid-September \\
Q. robur & 26 & 8.0 & 3.2 & $6.0 / 5.2$ & 10 & mid-September \\
\hline
\end{tabular}

After collection, acorns were soaked in water, and all those still floating after $5 \mathrm{~min}$ were considered nonviable and removed (Nyandiga \& McPherson 1992, Kennedy et al. 2004). The remaining acorns were air dried and stored in $5-\mathrm{ml}(0.127 \mathrm{~mm})$ polyethylene bags, which are permeable to carbon dioxide and oxygen, but largely imper- meable to moisture (Bonner \& Vozzo 1987), under temperature of $3 \pm 1{ }^{\circ} \mathrm{C}$.

Prior to storage, 100 acorns were randomly selected so that certain basic acorn morphological characteristics could be measured (Fig. 1). Acorn mass $(3.93 \pm 1.31 \mathrm{~g}$ for $Q$. variabilis, $2.07 \pm 0.47 \mathrm{~g}$ for $Q$. wutaishanica and $2.23 \pm 0.46 \mathrm{~g}$ for $Q$. robur) was mea-

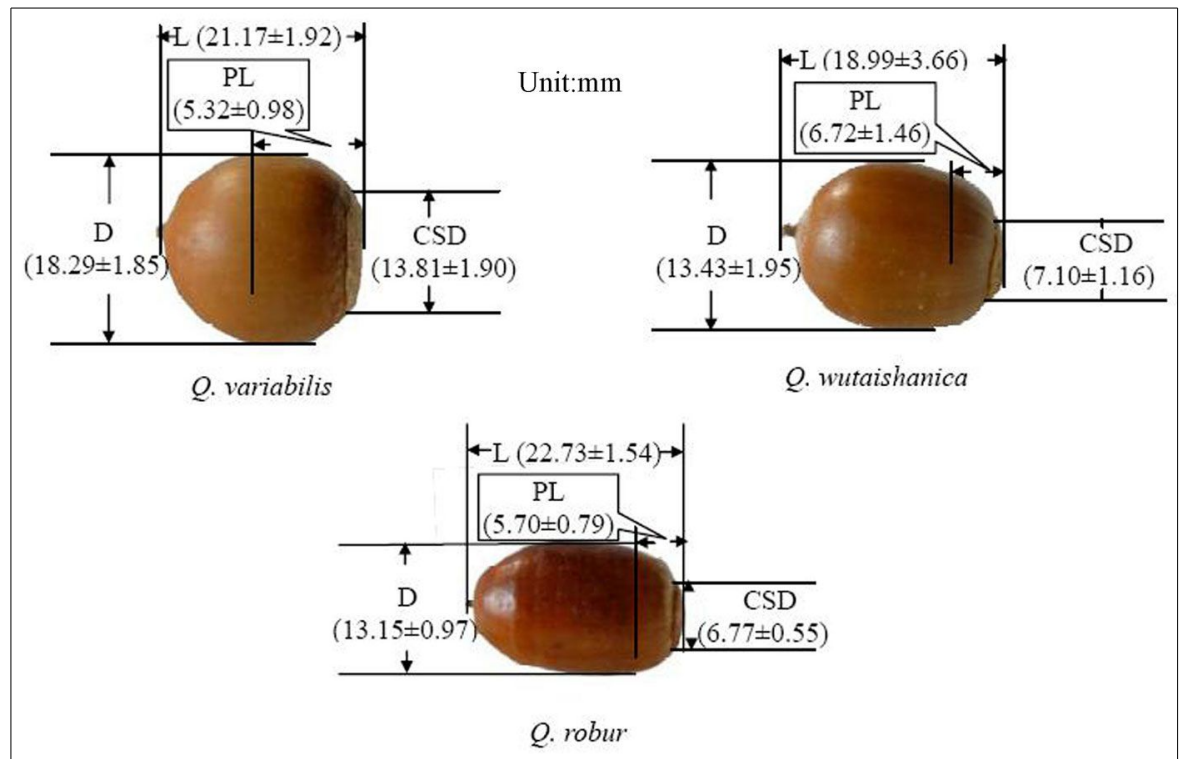

Fig. 1 - Profile of Quercus variabilis, Q. wutaishanica and $Q$. robur acorn measurement. (L): Length; (PL): Package length; (D): Diameter; (SCD): Diameter of cup scar.

Fig. 2 - The schematic diagram of different mechanical treatments applied to $Q$. variabilis acorns. (CK): control; (RS): removal of cup scar; (RP): removal of pericarp; (HC): removal of pericarp and half of the cotyledon; (TC): removal of pericarp and $2 / 3$ of the cotyledon.

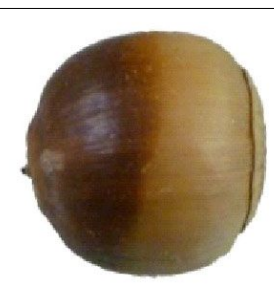

CK

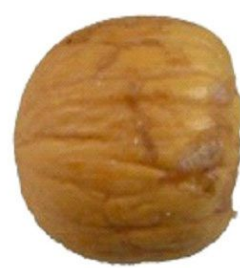

$\mathrm{RP}$
RS

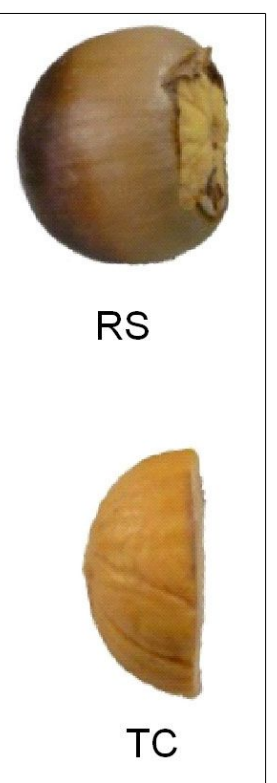

sured using a 1/1000 electronic balance. Acorn length, package length, diameter, pericarp thickness and diameter of the cup scar were determined by a vernier caliper. The difference in pericarp thickness at the apex, middle, and base of acorns was recorded to determine whether or not pericarp thickness had an effect on acorn germination.

\section{Germination tests}

To test the effect of pericarp and cotyledon on root and shoot emergence and establishment, the acorns of each species were randomly assigned to one of the following mechanical scarification treatments or categories (Fig. 2): (1) the control (CK); (2) removal of the cup scar (RS); (3) removal of the pericarp (RP); (4) removal of the pericarp and half of the cotyledon (HC); (5) removal of the pericarp and $2 / 3$ of the cotyledon (TC). On September 19, 2009, 15 acorns from each category were placed onto three pieces of filter paper moistened with distilled water in petri dishes $(11.5 \mathrm{~cm}$ diameter $)$ at a constant temperature of $25^{\circ} \mathrm{C}$ with 8 hours light in an incubator. Each category had three replicates. As acorns germinated, root (the length of radicle being longer than acorn length) and shoot emergence were checked every seven days, and the length of all roots and shoots was measured at the end of the experiment (137 days).

Germination percentage $(G P)$, vigor index $(V I)$, mean germination time $(\bar{t}-$ Ranal \& Santana 2006) and the synchronization index (Z - Ranal \& Santana 2006) of roots and shoots were calculated using the following formulae (eqn. 1 to 4):

$$
\begin{gathered}
G P(\%)=\frac{\sum n_{i}}{T} \cdot 100 \\
V I=G I \cdot S \\
\bar{t}=\frac{\sum_{i=1}^{k} n_{1} t_{i}}{\sum_{i=1}^{k} n_{1}} \\
Z=\frac{\sum C_{n_{i}, 2}}{N}
\end{gathered}
$$

where (eqn. 5 to 7 ):

$$
\begin{gathered}
C_{n_{i, 2}}=n_{i}\left(n_{1}-1\right) / 2 \\
N=\sum n_{i}\left(\sum n_{i}-1\right) / 2
\end{gathered}
$$




$$
G I=\frac{\sum n_{i}}{t_{i}}
$$

In these formulae, $n_{\mathrm{i}}$ refers to the number of seeds germinated in time $i$ (not the accumulated number, but the number corresponding to the $i^{\text {th }} C_{\mathrm{n}_{1}, 2}$ observation); $T$ is the total number of tested seeds; $S$ represents the average length of root and shoot on the $137^{\text {th }}$ day; $t_{\mathrm{i}}$ refers to the time from the start of the experiment to the $i^{\text {th }}$ observation (days); and $k$ is the last germination time.

\section{Statistical analyses}

Analysis of variance (ANOVA) was used to compare differences in the final root and shoot emergence rate and length, $\bar{t}, Z, V I$ and pericarp thickness among different mechanical scarifications. The results were expressed in percent, and data were transformed using arcsin for ANOVA analyses. All statistical tests were performed using the software package SPSS $^{\circledR}$ version 11.5 (IBM, NY, USA) and considered significant at $P=0.05$.

\section{Results}

Effect of different mechanical treatments on acorn emergence

$\mathrm{RP}, \mathrm{HC}$ and TC treatments all caused a significant increase in the root and shoot final germination rate of $Q$. variabilis acorns when compared to control acorns (Fig. 3). Acorns of $Q$. variabilis and $Q$. robur from the TC treatment had significantly lower root and shoot germination rates than those from the RP and $\mathrm{HC}$ treatments, while those of $Q$. wutaishanica had no significant difference from those from the former treatments. There was no significant difference in root and shoot germination rate between RS and control treatments for all three species.

When the germination experiment was completed, some acorns had only roots (Fig. 4). RP, HC and TC treatments significantly reduced the percentage of only roots for $Q$. variabilis, while decreasing that of $Q$. wutaishanica, and having no effect on that of Q. robur acorns (Fig. 4).

Effect of pericarp and cotyledon on root and shoot mean germination time

Removing the pericarp and cutting off the distal end of the cotyledon could give rise to faster root and shoot emergence. The first roots of $Q$. variabilis, $Q$. wutaishanica and Q. robur acorns from the $\mathrm{RP}, \mathrm{HC}$ and $\mathrm{TC}$ treatments emerged 9, 9 and 10 days after incubating, respectively, which amounted to 7 , 28 and 21 days earlier than those of the control treatment (Fig. 3). The first shoots of RP and $\mathrm{HC}$ acorns emerged 4, 3 and 3 weeks faster than those of the control treatment, while the first shoots of TC acorns emerged one week later than those of RP and $\mathrm{HC}$ treatments (Fig. 3). All RP, HC and TC treatments significantly reduced the root and shoot mean germination time of $Q$. variabilis, $Q$. wutaishanica and $Q$. robur acorns (Fig. 5). The root mean germination time of $Q$. wutaishanica and $Q$. robur acorns and the shoot mean germination time of $Q$. variabilis and $Q$. robur acorns were significantly decreased by RS compared with those under control condition.

Effect of the pericarp and cotyledon on root and shoot synchronization index

$Q$. variabilis, $Q$. wutaishanica and $Q$. robur acorns from the RP, HC and TC treatments showed a much higher synchronization index than those from the control treatment (Fig. 6). No significant difference was observed between RS and the control treatments for $Q$. variabilis and $Q$. wutaishanica acorns.

Effect of the pericarp and cotyledon on root and shoot vigor index and length

$\mathrm{RP}$ and HC treatments significantly improved the root and shoot vigor index of $Q$. variabilis, $Q$. wutaishanica and $Q$. robur acorns (Fig. 7). The root vigor index of $Q$.
Fig. 3 - The effects of five mechanical scarification treatments on root and shoot emergence from $Q$. variabilis (A), Q. wutaishanica (B) and $Q$. robur $(\mathrm{C})$ acorns. (CK): the control; (RS): removal of cup scar; (RP): removal of pericarp; (HC): removal of pericarp and $1 / 2$ of the distal end of cotyledon;

(TC): removal of pericarp and $2 / 3$ of the distal end of cotyledon.
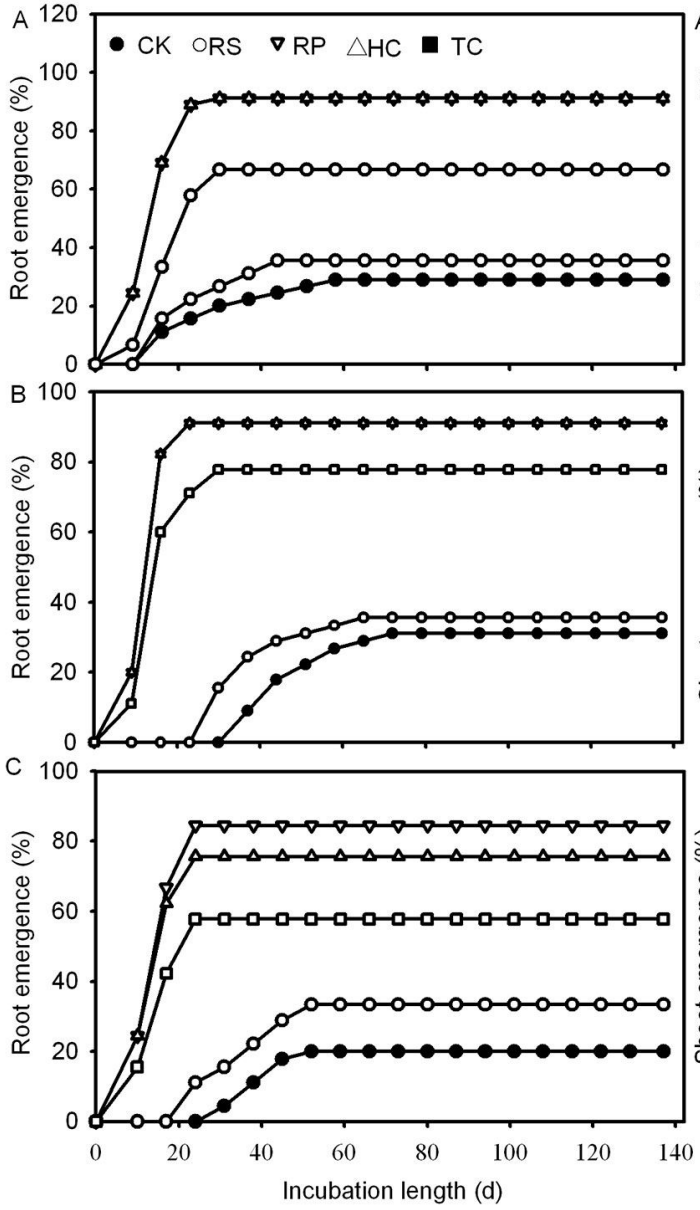
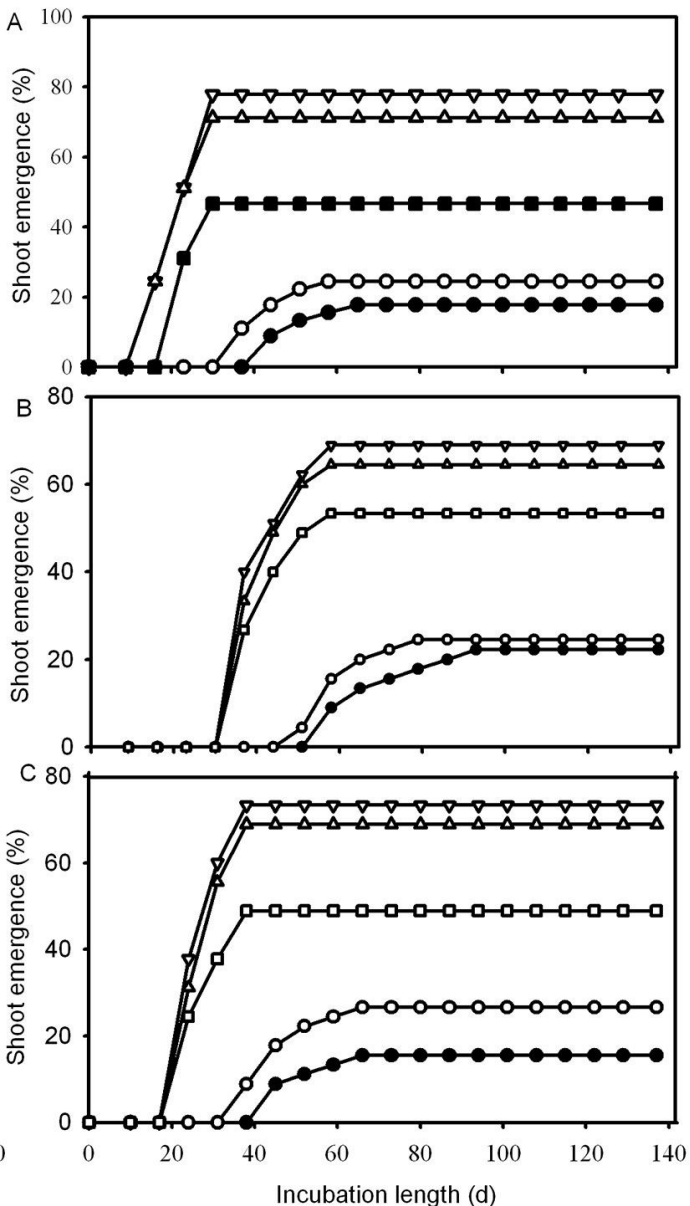


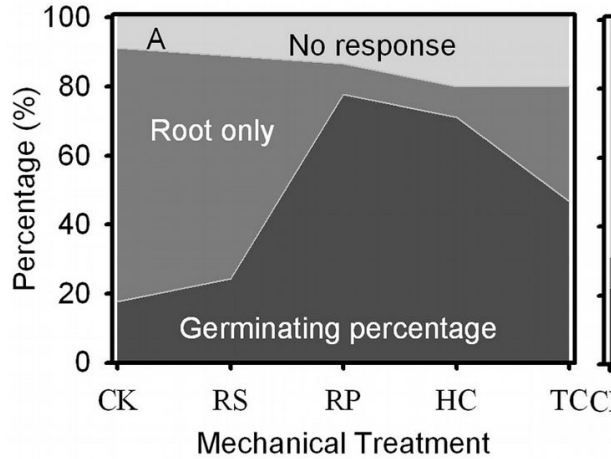

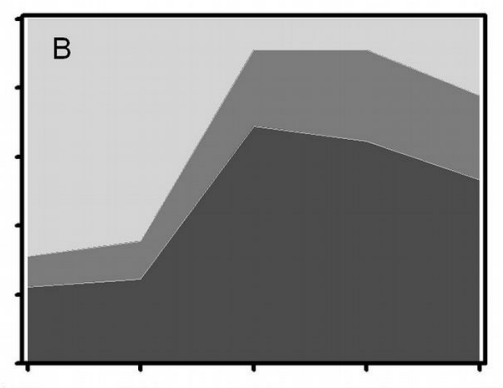

RS RP $\quad \mathrm{HC}$

Mechanical Treatment

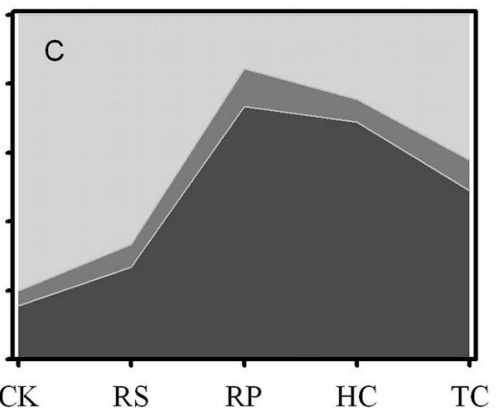

Mechanical Treatment

Fig. 4 - Percent of germinating, rooting and non-germinating acorns at the end of the 137-day study period for Q. variabilis (A), Q. wutaishanica (B) and Q. robur (C) acorns. Using the packing diagram area to represent the ratio of germinated acorns, only roots emerged acorns and non-germinated acorns under different mechanical treatments. (CK): the control; (RS): removal of cup scar; (RP): removal of pericarp; (HC): removal of pericarp and 1/2 of the distal end of cotyledon; (TC): removal of pericarp and 2/3 of the distal end of cotyledon.
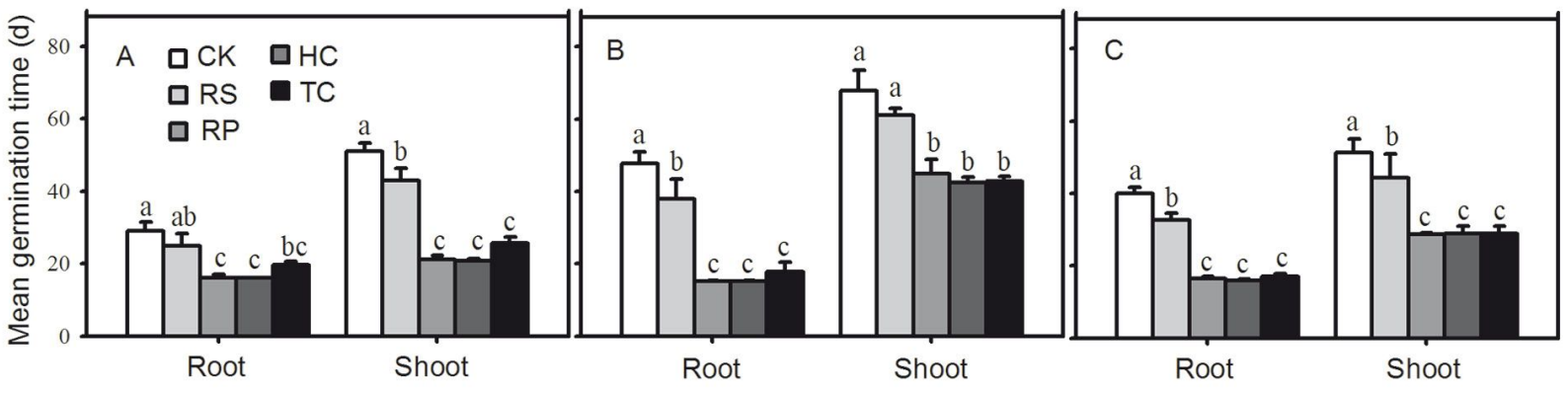

Fig. 5 - Mean germination time of root and shoot from $Q$. variabilis (A), Q. wutaishanica (B) and $Q$. robur (C) acorns. Means with the same letter are not significantly different from each other $(\mathrm{P}>0.05)$ after the Scheffe's test. Error bars represent the standard deviation from the mean.
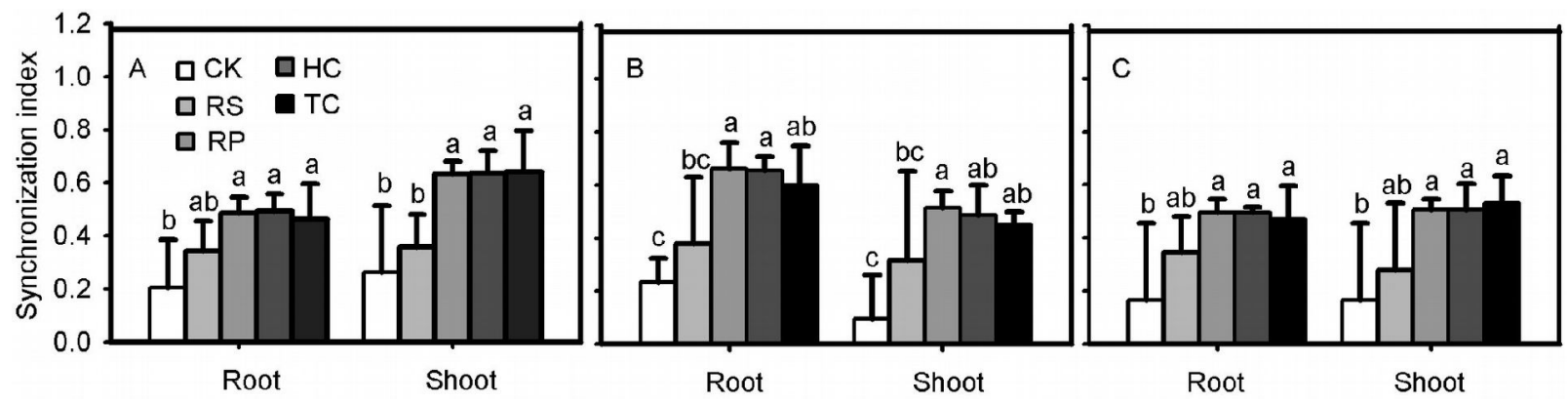

Fig. 6 - Synchronization index of root and shoot for $Q$. variabilis (A), Q. wutaishanica (B) and Q. robur (C) acorns. Means with the same letter are not significantly different from each other $(\mathrm{P}>0.05)$ after the Scheffe's test. Error bars represent the standard deviation from the mean.
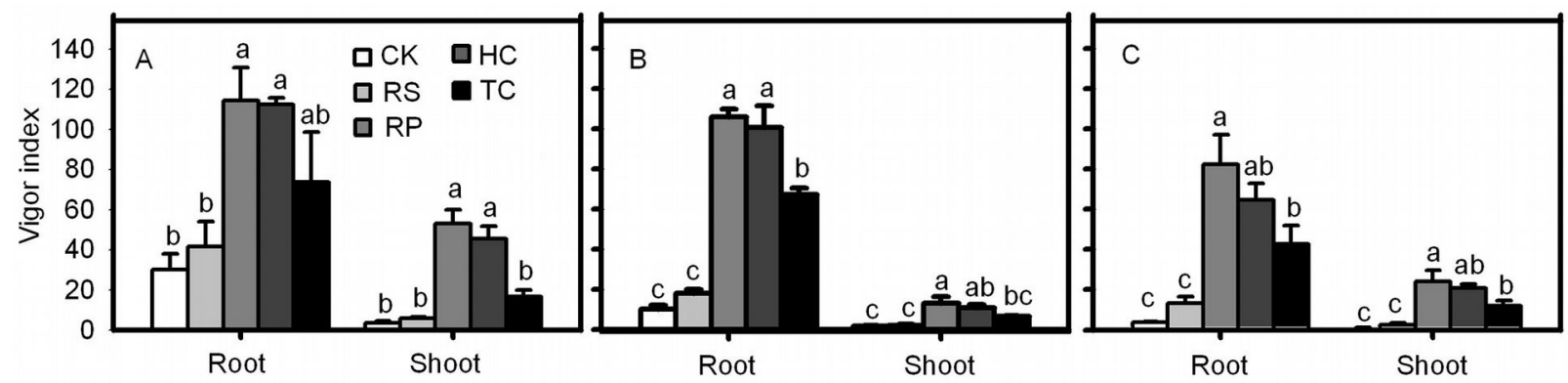

Fig. 7 - Vigor indexes of root and shoot from Q. variabilis (A), Q. wutaishanica (B) and Q. robur (C) acorns. Means with the same letter are not significantly different from each other $(\mathrm{P}>0.05)$ after the Scheffe's test. Error bars represent the standard deviation from the mean. 

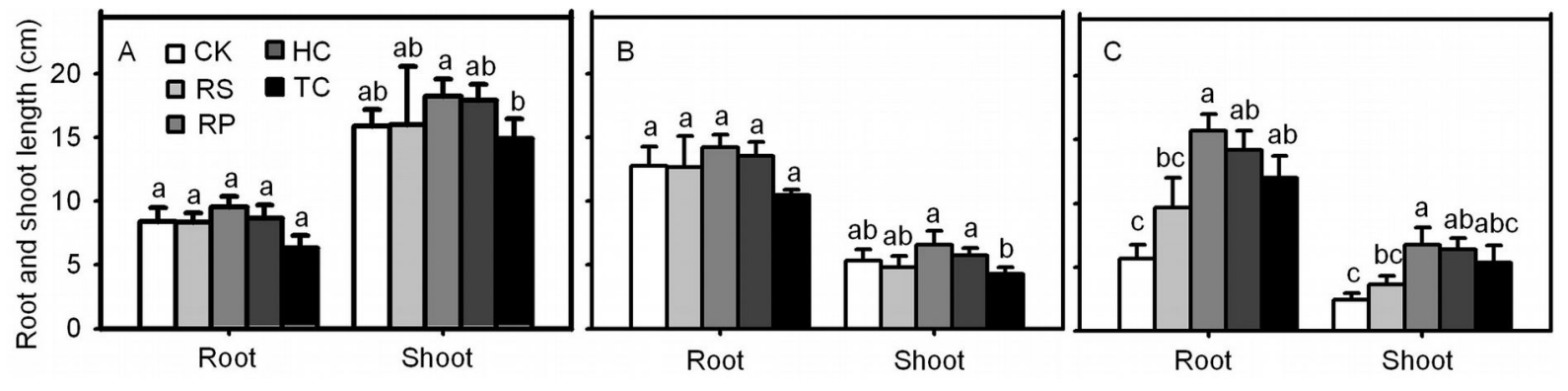

Fig. 8 - Influence of experimental treatments on mean root length and shoot height (cm) for Q. variabilis (A), Q. wutaishanica (B) and $Q$. robur $(\mathrm{C})$ acorns at the end of the experiment. Means with the same letter are not significantly different from each other $(\mathrm{P}>0.05)$ after the Scheffe's test. Error bars represent the standard deviation from the mean.

variabilis and $Q$. wutaishanica acorns from the TC treatment was significantly higher than those from the control, but no significant differences were detected among TC, $\mathrm{RP}$ and $\mathrm{HC}$ treatments. The shoot vigor index of $Q$. variabilis and the root and shoot vigor index of $Q$. robur acorns from the TC treatment were much higher than the control, but significantly lower than those from the $\mathrm{RP}$ and $\mathrm{HC}$ treatments. The root and shoot vigor index of the three species from RS and the control were not significantly different (Fig. 7). The final root emergence of $Q . v a-$ riabilis, $Q$. wutaishanica and $Q$. robur acorns from the RS treatment was not significantly different from the control (Fig. 7). A similar result was detected in the final shoot emergence of the three species.

The final root length and shoot height of $Q$. variabilis and $Q$. wutaishanica acorns were not significantly different from the roots and shoots from the RP, HC, TC and RS and the control (Fig. 8). However, $Q$. robur acorns from the RP and HC treatments had significant higher root length and shoot height than the control. The final root length of $Q$. robur acorns from the TC treatment was significantly longer than those from the control, but the final shoot height showed no significant different between the oaks subjected to the TC treatment and the control treatment.

\section{Effect of pericarp thickness on acorn germination}

A significant difference was found in pericarp thickness at the base, middle and apex of $Q$. wutaishanica and $Q$. robur acorns, and no significant difference was found for the Q. variabilis acorns (Fig. 9). Pericarp thickness of $Q$. wutaishanica and $Q$. robur acorns at the base and apex and at the base and medial was significantly lower than that at other sections; however, no difference was observed between the two lower parts. The pericarp thickness of $Q$. wutaishanica acorns was significantly thinner than that of $Q$. $v a$ riabilis and $Q$. robur acorns.

\section{Discussion}

\section{Effects of different treatments on acorn} germination

Mean germination time was used as the in-

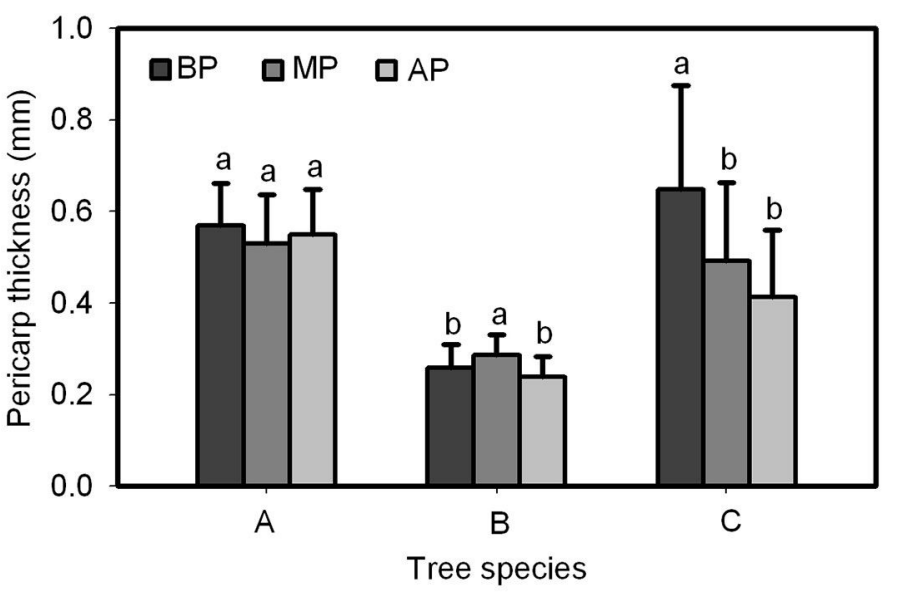

Fig. 9 - The comparison of pericarp thickness at the apex, middle, and base of $Q$. variabilis (A), Q. wutai-shanica (B) and $Q$. robur (C) acorns. Means with the same letter are not significantly different $(\mathrm{P}>0.05)$ after the Scheffe's test. Error bars represent the standard deviation from the mean. (BP): pericarp thickness at the base of acorns; (MP): pericarp thickness at the middle of acorns; (AP): pericarp thickness at the apex of acorns.

dex to evaluate the phenomenon of germination speed of oak acorns. It is a measurement of the average length of time required for maximum germination of a seed lot (Ranal \& Santana 2006). RP, HC and TC treatments significantly reduced root and shoot mean germination time for $Q$. variabilis, $Q$. wutaishanica and $Q$. robur acorns, indicating that the three treatments can induce faster root and shoot emergence for the acorns of these species, which is in accordance with results from Giertych \& Suszka (2011). The results are also consistent with the effects of cutting off approximately $1 / 3$ of the distal end of acorns (Suszka 2006). The acorns of the three species under the same treatment had similar root and shoot mean germination times. One reason for faster germination results from a more rapid penetration of water into the acorn (Finch-Savage \& Clay 1994). Another explanation is that increased levels of plant growth regulators were provoked, especially of IAA - indole-acetic acid (Finch-Savage \& Clay 1994, Prewein et al. 2006), which is closely related to water uptake. Moreover, cotyledons of $Q$. wutaishanica and $Q$. robur acorns separate rapidly when they absorb water, which improves water access to the embryonic axis (Bonner \& Vozzo 1987).

The synchronization index can describe acorn emergence patterns, with a higher index representing a more uniform germination. The root and shoot synchronization index of $Q$. variabilis and $Q$. wutaishanica acorns from the RP, HC and TC treatments was significantly higher than those from the control, illustrating that the three treatments can promote simultaneous germination. The reason may be that removing pericarp and cutting off the distal end of acorns causes faster root and shoot emergence, and reduces root and shoot germination time, causing the majority of roots and shoots to emerge in a shorter period.

$\mathrm{RP}, \mathrm{HC}$ and TC treatments significantly increased the root and shoot emergence as well as the final germination rate of Q.variabilis, $Q$. wutaishanica and $Q$. robur acorns, a finding similar to those of other studies on wa- 
ter oak acorns (e.g., Q. nigra L. - Bonner 1968, Bonner \& Vozzo 1987). ISTA (1999) also showed that removing the acorn pericarp and cup scar has a positive impact on acorn emergence. The reasons for this positive impact is that removing the pericarp can reduce the resistance of the radicle to pierce the pericarp, which can improve acorn water uptake and gas exchange (Brown \& Mogensen 1972, Peterson 1983, Sobrino-Vesperinas \& Viviani 2000). Moreover, Bonner \& Vozzo (1987) have indicated that an acorn is a raw material rich in tannins, which can inhibit radicle emergence. The presence of inhibitory substances has also been confirmed in the pericarps of mature Quercus nigra acorns (Peterson 1983) and in the embryo and cotyledon of Quercus aliena var acuteserrata acorns (Liu et al. 2012). RP, $\mathrm{HC}$ and TC treatments had different effects on enhancing the development of roots but not of the shoots of all three species.

No significant difference was found in the root and shoot mean germination time, synchronization index and final germination rate of $Q$. variabilis, $Q$. wutaishanica and $Q$. robur oak acorns between the RS and the control treatments. This finding is consistent with the effect of RS treatment carried out by Liu et al. (2012), but not with the findings of Rakić et al. (2006), who reported that removing the cup scar of $Q$. robur acorns can significantly improve the shoot percentage from 18 to $89 \%$. Although RS treatment can alleviate some of the mechanical strength, the main mechanical resistance of the pericarp is not removed, as the radicle breaks through at the acorn apex, where a powerful internal binding force is present. In addition, germination inhibitors may have impacted our results.

\section{Effects of the different treatments on} root and shoot vigor index and length

Vigor index, a comprehensive account of acorn germination and seedling growth, is a suitable index to evaluate seed vigor. $Q$. variabilis and $Q$. wutaishanica acorns from RP and HC treatments had a markedly higher root and shoot vigor index than those from the control. However, TC treatment only significantly improved the root vigor index of $Q$. wutaishanica and $Q$. robur acorns and the shoot vigor index of $Q$. robur acorns, indicating that RP and $\mathrm{HC}$ treatments have a stronger effect on increasing acorn vigor than the TC treatment. No significant difference was observed in the root length and shoot height of $Q$. variabilis, $Q$. wutaishanica and $Q$. robur acorns among RS, RP, $\mathrm{HC}, \mathrm{TC}$ and control treatments. These results are supported by previous works by Bonner \& Vozzo (1987) and Andersson \& Frost (1996). Fukumoto \& Kajimura (2000) argue that removing too much of the cotyledon $(1 / 2$ and $1 / 3)$ has a negative effect on the growth of $Q$. variabilis. This negative effect may be because, even if nutrients reserved in the cotyledon exceed those used in acorn germination, removing too much of the cotyledon can cause nutrient deficiencies.

\section{Relationships between pericarp}

thickness and acorn germination

Our hypothesis was that pericarp thickness has a positive effect on acorn germination. However, Q. wutaishanica acorns, having the lowest pericarp thickness, emerged 21 and 6 days later than $Q$. variabilis and $Q$. robur acorns, respectively, indicating that thinner pericarp thickness may not lead to faster germination. Pericarp thickness at the middle $Q$. wutaishanica acorns was the thickest, but for $Q$. robur, it was thickest at the base of the acorns. However, no significant difference in pericarp thickness was observed between the base, middle and apex of Q. variabilis acorns, which was inconsistent with the findings of Hou et al. (2010), who reported that pericarp thickness at the base and middle parts was significantly lower than at the apex. Our results indicate that pericarp thickness does not correlate with faster or higher acorn germination rates. Sobrino-Vesperinas \& Viviani (2000) illustrated that microstructures of the pericarp at the cupule and the apex of acorns that can restrain water are different from other parts of the pericarp. Therefore, the acorn pericarp anatomy appears to have a closer relationship with acorn germination than pericarp thickness.

\section{Conclusions}

Mechanical treatments before sowing have their advantages. RP and $\mathrm{HC}$ treatments significantly decreased root and shoot mean germination time, increased rooting and shooting germination percentage, and improved the root and shoot synchronization and vigor indexes of the three species' acorns, which effectively accelerated germination and regular seedling. Based on our results, removing the pericarp or cutting off $1 / 2$ of the cotyledon would be optimal for seedling producers.

\section{Acknowledgements}

We are very grateful to Lily van Eeden for various useful suggestions and for correcting the language of this paper. Yan Liu and Longyu Hou have contributed equally to this work. Conceived of and designed the experiments: Qingmei Li, Yan Liu, Longyu Hou. Conducted the experiments: Yan Liu, Longyu Hou. Analyzed the data: Yan Liu. Contributed reagents / materials / analysis tools: Qingmei Li. Wrote the paper: Yan Liu. The study was carried out at Research Institute of Forestry, Chinese Academy of Forestry, Beijing (China).

The work has been funded by the General
Financial Grant from China Postdoctoral Science Foundation grant 2014M550886, National Basic Research Program of China (973 Program) grant 2010CB951301-6 and the National Key Project of Scientific and Technical Supporting Programs of China under grants 2006BAD09B06 and 2006BAD 03A0308.

\section{References}

Andersson C, Frost I (1996). Growth of Quercus robur seedlings after experimental grazing and cotyledon removal. Acta Botanica Neerlandica 45: 85-94. - doi: 10.1111/j.1438-8677

Bonner FT, Vozzo JA (1987). Seed biology and technology of Quercus. General Technical Report SO-66, Southern Forest Experiment Station, USDA Forest Service, New Orleans, USA, pp. 34. [online] URL: http://nsl.fs.fed.us/SeedBiolo gyandTechnologyofQuercus.pdf

Bonner FT (1968). Water uptake and germination of red oak acorns. Botanical Gazette 129: 83-85. - doi: 10.1086/336416

Brown RC, Mogensen HL (1972). Late ovule and early embryo development in Quercus gambelii. American Journal of Botany 59: 311-316. - doi: $10.2307 / 2441434$

Dalling JW, Harms KE (1999). Damage tolerance and cotyledonary resource use in the tropical tree Gustavia superba. Oikos 85 (2): 257. - doi: $10.2307 / 3546491$

Finch-Savage WE, Clay HA (1994). Water relations of germination in the recalcitrant seeds of Quercus robur L. Seed Science Research 4: 315 322. - doi: 10.1017/S096025850000235X

Frost I, Rydin H (1997). Effects of competition, grazing and cotyledon nutrient supply on growth of Quercus robur seedlings. Oikos 79: 53-58. doi: $10.2307 / 3546089$

Fukumoto H, Kajimura H (2000). Effects of insect predation on hypocotyl survival and germination success of mature Quercus variabilis acorns. Journal of Forest Research 5: 31-34. - doi: 10.1007/BF02762760

Giertych MJ, Suszka J (2010). Influence of cutting off distal ends of Quercus robur acorns on seedling growth and their infection by the fungus Erysiphe alphitoides in different light conditions. Dendrobiology 64: 73-77. [online] URL: http://agro.icm.edu.pl/agro/element/bwmeta1.ele ment.agro-a651cbf8-b948-41c6-a44b-b806b301 346e/c/64_73_77.pdf

Giertych MJ, Suszka J (2011). Consequences of cutting off distal ends of cotyledons of Quercus robur acorns before sowing. Annals of Forest Science 68: 433-442. - doi: 10.1007/s13595-01 1-0038-6

Hou X, Yi X, Yang Y, Liu W (2010). Acorn germination and seedling survival of $Q$. variabilis effects of cotyledon excision. Annals of Forest Science 67 (7): 711. - doi: 10.1051/forest/2010 036

Hulme PE, Benkman CW (2002). Granivory. In: "Plant-Animal Interactions: An Evolutionary Approach" (Herrera CM, Pellmyr O eds). Blackwell, Oxford, UK, pp. 77-106. [online] URL: 
http://books.google.com/books?id=u4jAB7_7srs $\mathrm{C}$

ISTA (1999). Proceedings of the International Seed Testing Association. International rules for seed testing. Seed Science Technology 27: 1333.

Kabeya D, Sakai S (2003). The role of roots and cotyledons as storage organs in early stages of establishment in Quercus crispula: a quantitative analysis of the nonstructural carbohydrate in cotyledons and roots. Annals of Botany 92: 537 545. - doi: 10.1093/aob/mcg165

Kennedy PG, Hausmann NJ, Wenk EH, Dawson TE (2004). The importance of seed reserves for seedling performance: an integrated approach using morphological, physiological, and stable isotope techniques. Oecologia 141: 547-554. doi: 10.1007/s00442-004-1686-0

Liu Y, Liu G, Li Q, Liu Y, Hou L, Li GL (2012). Influence of pericarp, cotyledon and inhibitory substances on Sharp Tooth Oak (Quercus aliena var. acuteserrata) germination. PLoS One 7 e47682. - doi: 10.1371/journal.pone.0047682

Nyandiga CO, McPherson GR (1992). Germination of 2 warm-temperate oaks, Quercus emoryi and Quercus arizonica. Canadian Journal of Forest Research 22: 1395-1401. - doi: 10.1139/x9 2-185
Peterson JK (1983). Mechanisms involved in delayed germination of Quercus nigra L seeds. Annals of Botany 52: 81-92. [online] URL: http:// aob.oxfordjournals.org/content/52/1/81.short

Prewein C, Endemann M, Reinohl V, Salaj J, Sunderlikova V, Wilhelm E (2006). Physiological and morphological characteristics during development of pedunculate oak (Quercus robur L.) zygotic embryos. Trees 20: 53-60. - doi: 10.1007/s00468-005-0012-8

Rakić S, Povrenovic D, Tesevic V, Simic M, Maletic R (2006). Oak acorn, polyphenols and antioxidant activity in functional food. Journal of Food Engineering 74: 416-423. - doi: 10.1016/j. jfoodeng.2005.03.057

Ranal M, Santana DG (2006). How and why to measure the germination process. Revista Brasileira de Botanica 29 (1): 1-11. - doi: 10.1590/ S0100-84042006000100002

Shimada T (2001). Nutrient compositions of acorns, and horse chestnuts in relation to seedhoarding. Ecological Research 16 (4): 803-808. doi: 10.1046/j.1440-1703.2001.00435.x

Siemens DH, Lischke H, Maggiulli H, Schürchl, Roy BA (2003). Cost of resistance and tolerance under competition: the defense-stress benefit hypothesis. Evolutionary Ecology 17 (3): 247-263. - doi: 10.1023/A:1025517229934
Sobrino-Vesperinas E, Viviani AB (2000). Pericarp micromorphology and dehydration characteristics of Quercus suber L. acorns. Seed Science Research 10: 401-407. - doi: 10.1017/S09602 58500000441

Suszka B (2006). Generative propagation. In: "Deby (Quercus robur L, O. petraea (Matt) Liebl) - Nasze drzewa lesne Bogucki Wydawnic - two Naukowe" (Bugala W eds). Poznan, Poland, pp. 305-388.

Suszka B, Muller C, Bonnet-Masimbert M (2000). Nasiona Drzew Lesnych. Odzbioru do siewu [Seeds of forest broadleaves from harvest to sowing]. PWN, Warszawa-Poznan, Poland, pp. 307. [in Polish]

Takahashi A, Ichihara Y, Isagi Y, Shimada T (2010). Effects of acorn tannin content on infection by the fungus Ciboria batschiana. Forest Pathology 40: 96-99. - doi: 10.1111/j.1439-0329 .2009.00612.X

Yi XF, Yang YQ (2010). Large acorns benefit seedling recruitment by satiating weevil larvae in Quercus aliena. Plant Ecology 209: 291-300. doi: 10.1007/s11258-010-9730-0

Yi X, Zhang Z (2008). Influence of insect-infested cotyledons on early seedling growth of Mongolian oak, Quercus mongolica. Photosynthetica 46: 139-142. - doi: 10.1007/s11099-008-0022-z 